\title{
RAZONES HISTÓRICAS DE LA IMAGEN DEL EJÉRCITO ANTE LA SOCIEDAD ESPAÑOLA
}

\section{Fernando Ramos}

\section{Universidad de Vigo \\ RESUMEN}

La nueva concepción del Ejército español como instrumento al servicio de la causa de la paz internacional ha contribuido a configurar una nueva imagen que supere todos los tópicos y los prejuicios tan generalizados entre los ciudadanos sobre la institución armada. Dentro de ese marco, ésta pretende ser una reflexión documentada sobre la imagen que los españoles han tenido tradicionalmente de sus Ejércitos, particularmente del de Tierra, como consecuencia de las repetidas disfunciones de esta institución manifestadas en dos planos: por un lado, la propia ineficacia e incompetencia profesional del Ejército a la hora de cumplir satisfactoriamente, dentro de su ámbito específico, las misiones que tenía encomendadas, al tiempo que se sacrificaban inútil y repetidamente miles de vidas humanas; por otro, el papel de gendarme de su propio pueblo, de fuerza de ocupación desplegada sobre el territorio nacional, no para la defensa del mismo ante un enemigo externo, sino para conjurar cualquier movimiento del llamado "enemigo interior".

\section{Palabras clave: Ejército, defensa, España, Historia, Imagen}

\section{ABSTRACT}

The new conception of the Spanish Army since instrument to the service of the reason of the international peace has helped to form a new image that overcomes all the topics and the prejudices so generalized between the citizens on the armed institution. Inside this frame, this one tries to be a reflection documented on the image that the Spanish have had traditionally of his Armies, particularly of that of Earth, as consequence of the repeated ones dysfunctions of this institution demonstrated in two planes: on the one hand, the proper inefficiency and professional incompetence of the Army at the moment of expiring satisfactorily, inside his specific area, the missions that I had entrusted, at the time that they were sacrificing themselves uselessly and repeatedly thousands of human lives; for other one, gendarme's role of his own people, of force of occupation opened on the national territory, not for the defense of the same one before an external enemy, but to conspire any movement of the so called "enemigo interior".

Key Words Army, defense, Spain, history, image 


\section{(DESDE LA GUERRA DE CUBA A NUESTROS DÍAS)}

Ha constituido siempre un axioma la subordinación del Ejército al poder civil. No es preciso gastar mucho tiempo para demostrar la necesidad de que este postulado se cumpla. En otra forma resultaría imposible el gobierno de la nación y la existencia misma del Estado

(Teniente general Manuel Díez Alegría)

\section{LA INSTITUCIÓN Y LOS CIUDADANOS}

La desaparición del Servicio Militar Obligatorio y, consecuentemente, el sistema de reclutamiento basado en el llamamiento regular a filas, por reemplazos o cupos, de los ciudadanos en lo que se daba en llamar "edad militar", cierra un proceso histórico que se inicia a partir de la nueva Constitución democrática de 1978, que reconoce la objeción de conciencia, y la aparición de ciudadanos que esgrimen su derecho a no prestar servicio de armas a la nación o, simplemente, rechazan, como insumisos, sustituir "el deber de defender a España" por alguna otra contraprestación social.

La sustitución del modelo de recluta obligatoria por un ejército profesional, en pleno proceso de experimentación, no parece, por ahora, estar alcanzando las mínimas expectativas con que fue concebido. Se ha tenido que recurrir a extremar, hasta límites controvertidos, el margen de nivel cultural mínimo requerido a los futuros soldados y se han abierto los cuarteles a ciudadanos de países de origen hispano, hijos de españoles, sin que tampoco se haya logrado de este modo paliar la "falta de vocaciones" castrenses y cubrir las plantillas previstas.

Los problemas actuales del Ejército español no son, de otro lado, diferentes de los de cualquier otro ejército occidental. Son cuestiones de carácter técnico, que deben resolverse dentro de su propio ámbito. Pero la sociedad, que tan poco interés muestra por lo militar, ya no contempla con recelo los cuarteles.

La memoria histórica de los pueblos se nutre, poso a poso, de la propia experiencia contrastada por la realidad cotidiana, de los testimonios de las generaciones precedentes y de la síntesis necesaria de ambas fuentes. La imagen de una institución se configura lentamente a lo largo de los siglos en un proceso continuado y se transmite de generación en generación, de modo que algunos tópicos, no siempre resultado de hechos ciertos, sino de rumores y leyendas, se convierten en prejuicios inevitables.

Para situar nuestra reflexión, hemos elegido, a modo de secuencias cinematográficas, tres referentes bibliográficos, tres fuentes directas, tres testimonios incontestables, deliberadamente escogidos por su carácter ejemplar de otras tantas evidencias que conformaron la opinión de los españoles sobre sus ejércitos a lo largo del último siglo. 


\section{PRIMERA SECUENCIA: EL TESTIMONIO DE D. SANTIAGO RAMÓN Y CAJAL}

El Premio Nobel español fue médico militar en la campaña de Cuba. En sus autorizadas memorias, como uno de los últimos defensores de nuestro vestigio colonial, nos deja un desolador testimonio de la corrupción y la ineficacia del Ejército español y de la situación de penuria y abandono de unos desdichados soldados que mueren más por enfermedad y desnutrición que por las balas de los insurrectos.

Don Santiago descubre, al llegar a la enfermería San Isidro, en la Trocha del Este, que los alimentos que deben ser destinados a los soldados enfermos son cuidadosamente desviados por rancheros corruptos y oficiales sin conciencia, que se lucran y enriquecen con este infame negocio. Sigamos el propio testimonio de Cajal, que relata lo ocurrido, luego de poner los hechos en conocimiento del jefe de la Comandancia, quien no solamente no hace nada para poner fin a la situación descrita, sino que la califica de "chinchorradas":

Entre las impertinencias con que el comandante trató de molestarme, hubo una que estuvo a punto de provocar grave cuestión personal. En las noches de alarma (no raras en San Isidro), el comandante pretendía encerrar dos caballos suyos en el hospital, al lado de los enfermos, a fin de protegerlos contra los merodeadores; en justificación del capricho, alegaba que no cabían en el fortín de su residencia y que la enfermería era el sitio más seguro para guardarlos. Yo me opuse en varias ocasiones a tan antihigiénica pretensión, varias veces renovada, y el jefe, aunque refunfuñando, acababa por desistir. Perdida ahora la cordialidad, pensó, sin duda, que él no debía respetar mis escrúpulos. Y cierta noche, en que yo me hallaba acostado con fiebre alta, oí que traían los caballos a la sala, percibiéndose olor de cuadra insoportable. Vestíme deprisa y salí casi tambaleándome al encuentro de los palafreneros, a quienes rechacé a empellones, obligándolos a retirar el ganado. Noticioso entre tanto el jefe de lo ocurrido, vino furioso hacia mí, exclamando con voz alterada por la cólera:

-¿Quién es usted para desobedecerme? ¡Aquí represento la suprema autoridad, y usted tiene el deber de acatar ciegamente mis órdenes! ...

-Dispense usted -repliqué-; dentro de este recinto no hay más autoridad que la mía. Pesa sobre mí la responsabilidad del tratamiento y cuidado de los enfermos, y, en conciencia, no puedo consentir que por capricho de usted se convierta la sala en cuadra inmunda...

Ciego por la ira, y sin reparar en que estaba delante de un enfermo, se abalanzó en ademán de agredirme. Yo me puse a la defensiva, dispuesto a devolver golpe por golpe. La fiebre abrasaba mi cabeza, y hubo un momento en que todo lo vi rojo. Afortunadamente, los oficiales, harto más discretos que 
el comandante, comprendieron lo absurdo de la situación, y nos separaron y apaciguaron.

Conforme era de esperar, el jefe me instruyó sumario por insubordinación y amenazas a la autoridad. Comenzaron, pues, las actuaciones. Los folios crecían como espuma. Mi superior jerárquico propaló la especie de que no había de parar hasta mandarme a presidio. Para hacer buenas sus amenazas confiaba mucho en cierto tío suyo, el brigadier $Z$, habitante a la sazón en Santiago y personaje muy influyente en la Capitanía general. Mas al fin ocurrió lo que era de esperar. En cuanto, por mis declaraciones y denuncias, conocieron las autoridades de Puerto Príncipe las escandalosas filtraciones y los abusos de autoridad consentidos o cometidos por el jefe militar de San Isidro, todos, incluso el famoso general de quien tanto fiaba su sobrino, apresuráronse a echar tierra al asunto. De mi proceso, pues, nadie volvió a acordarse ya. $Y$ un oportuno relevo del comandante, fundado en motivos de salud -allí todos estábamos más o menos enfermos-, restableció definitivamente la paz en San Isidro.

De todos modos, yo salí con mi empeño de purificar, en lo posible, la administración del hospital. En lo sucesivo, irregularidades, malversaciones y chanchullos, si los hubo, redujéronse a un mínimo tolerable.

Cuán desconsolador para un corazón de patriota es, después de cuarenta y nueve años, reconocer que todavía buena parte de nuestros militares empleados y hasta próceres políticos siguen entregados al saqueo del Estadoii.

Si el relato de Ramón y Cajal es terrible, no lo es menos el contenido de la siguiente secuencia, que tiene como escenario, tras la derrota, la repatriación de los soldados y su llegada al puerto de Vigo.

\section{SEGUNDA SECUENCIA: LA INDIGNIDAD DEL GENERAL TORAL}

Los soldados que han defendido Cuba son repatriados enfermos, muchos de ellos fallecen por el camino y son sepultados en la mar. Cuando los transportes donde sobreviven hacinados llegan a Vigo, nada, salvo la caridad pública, la Cruz Roja o la solidaridad popular está dispuesta para recibirlos. FARO DE VIGO, decano de la prensa nacional, da cumplida cuenta de las patéticas escenas que se suceden en los muelles.

La tropa es obligada a permanecer largas horas en los barcos antes de ser desembarcada, en el mejor de los casos de que el transporte traiga "patente limpia" y no hayan de pasar interminables cuarentenas en el Lazareto de San Simón.

En uno de estos transportes regresa el general Toral, el mismo que ha rendido Santiago de Cuba. Este militar, que no ha sabido conducir a sus soldados a la victoria, ni si quiera tiene la gallardía de compartir dignamente con ellos el infortunio.

Tan pronto como el "León XIII", buque en el que viajan, atraca en Vigo, el 


\section{RAZONES HISTÓRICAS DE LA IMAGEN DEL EJÉRCITO ANTE LA SOCIEDAD ESPAÑOLA}

general Toral, sin esperar a que sean desembarcados enfermos, heridos 0 fallecidos, salta a tierra y se aloja en un hotel. Cuando la población se entera del vergonzoso comportamiento del general se produce un motín popular de tal envergadura, que Toral ha de regresar a bordo. Pero el relato completo de cómo son tratados los pobres soldados repatriados es todavía más esclarecedorii:

Abordo, sobre la cubierta del buque, se veía a los repatriados apiñados y deseosos de saltar a tierra. Cada vez había más soldados que pedían con insistencia agua para beber y uno de los que pedían agua fue agredido por un oficial. El capitán repatriado, Sr. Rodríguez, del primer batallón de Simancas, había dado un golpe con su sable a un soldado del pasaje del "León XIII" por el "delito" de haber pedido este recluta agua a los que se hallaban en el muelle. La agresión, que produjo al soldado Marcelino Martínez, de la 43 compañía del segundo batallón de Simancas, un profundo corte en la oreja, no pasó desapercibida para la multitud. La ola de protestas crecía y el alboroto se hacía mayor. Numerosos grupos, compuestos fundamentalmente por mujeres, en los que se escuchaban acusaciones contra las autoridades y contra la compañía ejecutora del regreso, la Trasatlántica, se dirigieron al edificio del Gobierno militar para reclamar el desembarque de la tropa. Los ánimos parecieron apaciguarse un poco cuando el general Núñez anunció su disposición a permitir el desembarque.

Pero la revuelta popular aún no había concluido. Hacia las 13.00 un grupo numerosísimo de personas apareció frente al Hotel Continental, donde se hospedaba el jefe de la expedición que conducía el "León XIII", el general Toral, el mismo que había firmado la capitulación de la plaza de Santiago de Cuba. Quizá fue la falta de tacto de este militar lo que exasperó la ira popular hacia su persona. Había sido el primero en saltar a tierra del buque, apresurándose a albergarse en su hospedaje sin aguardar a que antes fueran atendidos los soldados enfermos. Los manifestantes, que llegaron a sumar hasta un millar de personas, se congregaban ahora frente al Hotel Continental clamando entre gritos porque se permitiera el acceso al trasatlántico para asistir a los repatriados. A este clamor se sumaba la acusación otra vez contra la Compañía Trasatlántica por las pésimas condiciones en que habían llegado los repatriados. El tumulto adquiría por momentos caracteres de verdadera gravedad.

Desde el hotel, los manifestantes se dirigieron otra vez al muelle para esperar el desembarco de los repatriados, pero allí fueron interceptados por fuerzas de Carabineros y de la Guardia Civil. No obstante, los vecinos las arrollaron. Poco después llegaba al muelle el coche del gobernador militar de la plaza conduciendo al general Total, obligado a reembarcar en el vapor que lo había traído a España. Los manifestantes recibieron con silbidos al gobernador militar y apedrearon su coche. Medio a escondídas el general Total tomó una lancha para trasladarse de nuevo al "León XIII" y rectificar así el error de abandonar la nave antes de que lo hiciese el último de sus hombres. Los manifestantes apedrearon también esta lancha al tiempo que pedían a gritos que desembarcasen a los soldados y, cuando vieron a bordo al general Total, no cedieron en su actitud y siguieron arrojando piedras, ésta vez al buque, logrando romper gran número de cristales del vapor. 
Los que regresaron del puerto siguieron arrojando piedras a otros edificios y a las bombas del alumbrado público.

El general Toral ya no quiso desembarcar de nuevo en Vigo y tomó después desde el transatlántico una lancha que lo condujo a Redondela para esperar allí el tren de Madrid. También en Redondela el pueblo lo identificó, haciéndole objeto de otra manifestación hostil en la estación.

En Vigo, la tregua a un escándalo que pudo haber desembocado en un conflicto de mayores dimensiones la puso sobre las 14.00 el comienzo del desembarque. La Cruz Roja ya podía ahora ejercer su labor y lo hacía socorriendo a los enfermos y alimentando a los más delicados. Duró bastante el desembarque y cuando la cubierta del buque quedó despejada se sacó a los enfermos.

Este episodio, lamentable, figura en todas las memorias, antologías y recuerdos que se han publicado desde entonces en Vigo y forma parte de ese substrato popular y común que conforma la respuesta popular ante determinados estímulos.

\section{TERCERA SECUENCIA: EL EPISODIO DEL CORONEL ARAUJO TORRES Y SUS OFICIALES}

La campaña de Africa fue, para muchos militares, una guerra colonial a la puerta de casa. La ocasión de volver a ganar glorias y triunfos que hicieran olvidar el amargo sabor de la derrota del 98.

Pero otra vez la ineficacia, el corporativismo de casta, la corrupción y el desastre añadieron nuevos baldones a las tan mal honradas banderas.

Las campañas de Africa eran un pozo sin fondo donde España consumía los recursos que se sustraían al necesario desarrollo nacional, sacrificando inútilmente miles de vidas de hijos de su pueblo, para que una casta militar de casino, los africanistas, hiciera carreras meteóricas, con notable disgustos de sus compañeros destinados a las guarniciones peninsulares, que se defendieron con la insubordinación o la coacción al Gobierno, creando las Juntas de Defensa.

Hoy en día, existen evidencias del escaso rigor con que eran otorgadas cruces y medallas, en no pocas ocasiones a propuesta de los propios interesados, quienes, incluso, no satisfechos con la distinción pensionada que tan fácilmente obtenían, llegaban a reclamar (Franco lo hizo) "mejora de recompensa".

Indalecio Prieto, cronista y observador de la guerra de Africa, alude en sus escritos una atinada observación de un periódico militar de la época, donde se reconoce la descarnada inutilidad de aquella campaña, salvo para perder dinero y vidas, a cuya costa se cimentaban meteóricas carreras de militares de salón. Payne ${ }^{\text {iv }}$ recoge la cita completa:

Supongamos que nuestras tropas salen de Melilla y ocupan 10, 20, 30 o 100 kilómetros. Y bien, están ocupados. ¿Y con qué propósito? Con ninguno. Absolutamente ninguno, como no sea el de gastar cien millones o más de pesetas que tanta falta hacen en casa y que en Marruecos no sirven a ningún propósito. 


\section{RAZONES HISTÓRICAS DE LA IMAGEN DEL EJÉRCITO ANTE LA SOCIEDAD ESPAÑOLA}

Varios cientos de soldados morirían, muchos otros serían promovidos, una vez más mostraríamos nuestra falta de organización y nos pondríamos en ridículo por centésima vez llamando a unas cuantas balas perdidas una escaramuza, a una escaramuza una empresa militar, a una expedición de reconocimiento un combate, y a un combate una batalla campal...

Como ejemplo de una actuación que traspasa no ya el mínimo decoro que se debe esperar en un militar, sino la propia dignidad humana, cabe citar la sorprendente actuación, aun en situación tan extrema, del coronel Araujo y sus oficiales, hechos de los que da cumplida cuenta el informe del fiscal en el tristemente célebre expediente Picasso, exhumado por Antonio Carrasco García en su libro sobre las imágenes del denominado "Desastre de Annual".

El episodio se produce en la posición de Dar Quebdani, sitiada por los rifeños, donde se encuentra aun destacamento español. El coronel Araujo Torres, el jefe de mayor rango presente, y sus oficiales deciden rendirse y pagar 5.000 pesetas a sus sitiadores por su vida. Pactan con un emisario de los moros y ordenan a sus soldados que dejen las armas. Estos lo hacen. Los asaltantes ocupan la posición y pasan a cuchillo a los inermes defensores que han sido abandonados por sus jefes. Los rifeños cumplen con los indignos oficiales que se van de allí sin haber hecho nada por salvar a sus hombres.

Veamos el informe de lo sucedido:

Tras parlamentar con el jefe de los sitiadores y habiéndole hecho entrega del dinero, se ordena a la tropa que abandone las armas, momento que aprovechan los harkeños para lanzarse sobre los indefensos soldados, matando a unos 900 , pero conservando la vida de unos treinta oficiales que no han hecho nada para defender a sus hombres. Una vez consumada la matanza, retiraron a los oficiales que no han hecho nada por defender a sus hombres.

Se resalta en el informe que se marchan "porque ya nada tienen que hacer allí".

Estas tres secuencias, deliberadamente escogidas por su riqueza expresiva, alimentaron la memoria colectiva del pueblo español e incrementaron el recelo y la desconfianza hacia una institución a la que, finalmente, tras el episodio de la guerra civil, no se asignaba otra función que la de ser gendarme de su propio pueblo y garante de un determinado régimen político impuesto a éste.

Nada expresa mejor la propia opinión que los militares, entendido como ente corporativo, es decir, la masa de jefes y oficiales tenían de sí mismos ante la sociedad que el célebre episodio del "Cu-cut". Para situarnos ante este caso, hemos de retroceder a 1905. Como es sabido, el desencadenante de los graves sucesos posteriores fue una viñeta de la publicación catalanista en la que se ve a dos personajes conversando delante de un café donde se celebra "el banquete de la victoria”. Precisamente por ello, uno de ellos dice al otro: "¡Serán civiles!”.

Conviene tener presente que todavía está muy reciente la derrota de Cuba y que el Ejército, replegado sobre la propia sociedad a la que debería servir, es 
particularmente sensible a toda crítica.

La revista Nuevo Mundov, número 621, del jueves, 30 de noviembre de 1905, recoge, con amplio despliegue fotográfico, una crónica tan precisa de los hechos, que no es necesario añadir comentario alguno. (Por cierto que en portada aparece un retrato muy expresivo de la princisa Ena de Battenberg):

La campaña catalanista de algunos periódicos de Barcelona, sobre todo "La Veu de Catalunya" y el "Cu-cut", la forma en que desde algún tiempo se venía haciendo, había engendrado un hondo disgusto en la guarnición de dicha ciudad. Al anochecer del sábado último, eran en ella muchas las personas que daban por seguro que iban á ocurrir, con tal motivo, graves sucesos. A las ocho de la noche se celebró una reunión de autoridades para acordar las medidas que, en tal caso, debían tomarse. Según refirieron después varios periódicos, las autoridades militares apelaron a las medidas más enérgicas que las Ordenanzas permiten.

Pero esto no impidió que lo que los jefes y oficiales- de la citada guarnición se habían propuesto, se llevase á cabo. A las nueve menos cuarto fueron acudiendo a la plaza Real numerosos grupos de militares, todos de uniforme, excepto algunos que pertenecían á la guardia civil, y ostentando en el pecho condecoraciones.

Unos se sentaron en las mesas del "Café Español", otros paseaban.

A las nueve eran unos cuatrocientos. Un comandante, levantando en el centro de la plaza su bastón de mando, gritó: Caballeros, "Viva España". El grito fue unánimemente contestado y los militares, en masa compacta, se dirigieron por la calle de Fernando y Quintana la redacción del "Cu-cut".

Ante la redacción del "Cu-cut", los militares prorrumpieron en vivas a España y a Cataluña española. Uno de ellos reventó, con un hacha, la puerta de hierro, y un grupo entró por el boquete; otro se mantuvo a la puerta para evitar que interviniera la policía ni paisanos. Al poco tiempo empezaron a salir por la puerta los diversos objetos de la redacción e imprenta. El muñeco del "Cu-cut" fue despedazado; la máquina destrozada. La caja de caudales fue entregada intacta al gobernador. Ante el edificio se formó con los libros un gran montón y se le prendió fuego. De allí pasaron los militares a "La Veu de Catalunya". No se pudo violentar la puerta por ser maciza. Varios oficiales lograron, sin embargo, entrar por el balcón, y realizaron igual tarea que en el "Cu-cut".

Algunos años después de este episodio, la opinión que buena parte de la sociedad española, particularmente los intelectuales, tienen de los militares profesionales, queda descarnadamente reflejada en este apunte que Alfonso Daniel Rodríguez Castelao expresa en su libro "Sempre en Galiza"vi:

La bravura de los militares españoles era el miedo que metía miedo.

El cuartel era un convento donde se juraba, se blasfemaba, se conspiraba 


\section{RAZONES HISTÓRICAS DE LA IMAGEN DEL EJÉRCITO ANTE LA SOCIEDAD ESPAÑOLA}

contra el Gobierno, se pegaban bofetadas, se pelaban patatas y se tocaba la corneta. Allí, los jefes y oficiales escogían asistentes.

Los militares usaban bigote y padecían catarro crónico. Se adornaban con plumas, charoles, hierros y botones dorados para enamorar a las mujeres. Gustaban más de las procesiones que de las batallas. Perdían las guerras eso es verdad-; pero las perdían gloriosamente. Eran caballeros en el casino y arrieros en el hogar. Llegaban a generales por riguroso turno de antigüedad. Morían de prostatitis crónica (en los militares españoles todo era crónico).

\section{EL INJUSTO SISTEMA DE RECLUTAMIENTO}

La creación de los ejércitos nacionales y el concepto mismo de la causa nacional; es decir, un ejército de ciudadanos-soldados, como defensores del interés de la nación toda, es una de las grandes aportaciones de la Revolución Francesa. Los ciudadanos soldados vencieron a los mercenarios austríacos por una razón esencial: aquéllos defendían la Revolución, una causa común; los segundos peleaban por la paga.

La Edad Media conoció las mesnadas de siervos; los grandes ejércitos del Renacimiento eran, en realidad, masas de mercenarios, incluidos los famosos Tercios Españoles, que no fueron precisamente modelo de disciplina y cuyos motines y rebeliones, cuando la paga se retrasaba o el botín de los saqueos era insuficiente, son tan famosos como sus hazañas.

En 1704, los Borbones reinantes introducen el sistema de "Quintas", que con ligeras variantes, y vergonzosos abusos, han sobrevivido hasta nuestros días: consistía originariamente en el "sorteo" de uno de cada cinco soldados, en función de las listas municipales. En aquel sistema quedaban excluidos los nobles, los eclesiásticos y un sin fin de excepciones, a veces sencillamente pintorescas. Cuando un joven acomodado era designado para servir al Rey podía ser sustituido por cualquier pobre desgraciado, a cuyas espaldas se cargaban los ocho años de servicio.

El sistema nacional de reclutamiento español ha sido siempre injusto, cuando no vergonzoso. En 1836, Mendizábal crea el sistema de "redención" por el que, a cambio de 8.000 reales, los hijos de los terratenientes se libraban de servir a la nación. Los soldados saldrán de la masa de campesinos pobres, mal nutridos, analfabetos, mal vestidos y peor instruidos morirán en acciones absurdas bajo la dirección de oficiales incompetentes.

Los estudios al respecto concluyen que por cada soldado muerto en acción de guerra en las campañas de Cuba, Filipinas o Marruecos, hubo entre 15 y 20 bajas por enfermedad o mal nutrición. Cólera, fiebre amarilla, tifus, tuberculosis, viruela y disentería causaron más bajas que las balas enemigas.

El intento del general Luque, de imponer, en 1912, la obligación de que todos los ciudadanos en edad militar cumpliese el servicio personalmente naufragó antes 
de ser ensayada. Las clases pudientes lograron que se impusiera el sistema de "cuotas". Según la cantidad que se pudiera pagar (1.000 o 2.000 pesetas) solamente se cumplían cinco o diez meses. Los demás debían servir durante tres años. Diez mil de estos pobres soldados perderán la vida en las campañas africanas sin la menor utilidad.

\section{DEL EJÉRCITO DE LA VICTORIA A LAS FUERZAS ARMADAS}

\section{DE LA DEMOCRACIA}

"Los militares (hablamos de los militares profesionales) se han definido siempre como un grupo propio, aislado. "Se consideraban servidores del Estado escribe el historiador y militar Gabriel Cardona_, o más propiamente del Rey, pero de rango superior al de los funcionarios civiles. La aparatosidad de los uniformes compensaba la escasez de sueldo".

España va a ser subsidiaria durante cuarenta años de una experiencia singular. El Ejército de la Victoria, de una victoria sobre otros españoles, será el sostén esencial del régimen, la "columna vertebral de la patria", según la terminología al uso.

Cruces, medallas y laureadas perpetuarán la victoria de unos sobre otros. Navarra incorpora a su escudo la laureada colectiva por su aportación al bando de Franco durante la contienda. Años después, las autoridades forales tendrán la delicadeza de renunciar a este símbolo, reservado para el heroísmo militar en defensa de la comunidad, y no para la guerra civil.

El exceso de oficiales, dado el elevado número de "provisionales" (algunos apenas con unos años de bachiller) que se quedan en las unidades, trataba de aliviarse a través de la compuerta de los destinos civiles. Un conocido periodista gallego fue recluido en el calabozo del Regimiento de Caballería Talavera XIII, porque escribe un diálogo entre dos paisanas de la aldea, una de las cuales relata a otra que "su hijo estudiaba para coronel porque quiere entrar en Hacienda". La broma no se toleraba.

Manuel Fernández Areal, director de Diario Regional de Valladolid, fue sometido incluso a un consejo de guerra y condenado a pena de reclusión, en su calidad de oficial de milicias, por publicar un artículo proponiendo la sustitución del Ejército de recluta por profesionales.

La realidad del Ejército de la Victoria fue un permanente recordatorio de la tragedia civil: la bandera más condecorada, la de "Regulares 2", lo es, en gran medida, además de su participación en las guerras africanas, por la campaña de la 


\section{RAZONES HISTÓRICAS DE LA IMAGEN DEL EJÉRCITO ANTE LA SOCIEDAD ESPAÑOLA}

denominada "Cruzada de Liberación Nacional". De este modo, el palmarés de nuestros regimientos se tiñó con la sangre de unos españoles derramada por otros españoles. Franco instituyó "la banda y el cordón de la victoria": jefes y oficiales lucirán una banda o un cordón que recuerda la guerra civil permanentemente. Hasta la llegada de la democracia no será suprimido este símbolo de la lucha fratricida.

En los cuarteles se rendía homenaje a los caídos, ante monolitos, cuyas leyendas e inscripciones recordaban únicamente a las bajas del bando nacional. Para muchos, el Ejército nacional será para siempre el ejército del franquismo. Ese poso será difícil de borrar. La identificación entre franquismo y Ejército va a perdurar durante años. El Ejército asume la salvaguarda permanente del régimen y es el cuidador de sus esencias.

La transición democrática convirtió al Ejército en el "gran mudo". Se alababa su disciplina y sometimiento al poder civil, como si fuera algo excepcional. Durante la fase pre constitucional y la primera andadura de nuestra Carta Magna se sucedieron las actitudes abiertamente rebeldes de algunos mandos, antes y después del $23 \mathrm{~F}$, así como los manifiestos de jóvenes capitanes, además de abundantes desaires y muestras de indisciplina ante el teniente general Gutiérrez Mellado, pieza esencial de la controvertida reforma. Algunos altos mandos llegaron a reclamar y defender, durante ese periodo, la "autonomía militar", como si el Ejército no fuera, en definitiva, una institución más del Estado, sometida al poder civil como cualquier otra.

Superada la transición política, la actitud leal a la Constitución del conjunto de las Fuerzas Armadas, provocó que la sociedad comenzara a mirar hacia los cuarteles con una nueva confianza. Pese a la drástica reducción de efectivos que supuso, la modernización del Ejército de Tierra devolvió la ilusión profesional a amplios sectores de oficiales, a quienes se ofrecía una nueva perspectiva en su carrera, que culminaría cuando comenzaron a salir al exterior en misiones de paz.

\section{LA EVOLUCIÓN DE LA IMAGEN DEL EJÉRCITO ENTRE LOS ESPAÑOLES}

Hoy en día, la imagen que tienen los españoles de sus fuerzas armadas, del Ejército, se ha modificado de manera radical y, según revelan repetidamente las encuestas al respecto vii, hay dos variantes esenciales: es peor entre las mujeres que entre los hombres, y mejora según la edad de los encuestados.

Tradicionalmente, los mayores de 45 años suelen tener mejor concepto del Ejército que los menores de esa edad. Quienes fueron soldados, pese a reconocer críticamente las disfunciones históricas de la institución, compensan con los recuerdos de juventud, la camaradería, las bromas y los desahogos de aquellos días la impresión o incluso las experiencias negativas personales. En 1996, la mayoría de quienes pasaron por los cuarteles, de ser sinceras sus respuestas, no tenían inconveniente en que sus hijos repitieran la experiencia. 
Pero quienes prestaron el servicio militar antaño reconocían que en el cuartel se perdía mucho tiempo e incluso llegaban a definir el servicio militar como "no hacer nada a toda prisa". Era lo que ocurría en los aburridos regimientos de las viejas guarniciones, pero no en las unidades de élite, donde la preparación, la actividad y la exigencia eran netamente superiores.

Padecía excesivamente nuestro Ejército de lo que se ha llamado el "modelo dixoniano"; es decir, la vieja costumbre de destacar lo superfluo y hacer de lo complementario lo más relevante. Eso ocurre cuando los ejércitos, en lugar de entrenarse para el combate, la instrucción de las armas, la formación cultural y humana de sus soldados, la preparación global de su personal, solamente atiende a las formaciones de orden cerrado, la instrucción rutinaria en el patio, los desfiles y las procesiones, cosa harto frecuente en el pasado.

En ese sentido, el psicólogo Norman Dixon ${ }^{\text {viii }}$ advierte que estos rituales litúrgicos, repetidos más o menos en todos los ejércitos, tienen propensión a atraer a determinados tipos de individuos que pueden llegar a una amenaza si llegan a ocupar determinados puestos de mando. Acentuando las características de este tipo de militarismo, el más negativo de todos, Dixon señala: "Estas personas pueden sentirse atraídas por las organizaciones militares debido a que éstas han creado, por necesidades de propia subsistencia, mecanismos perfeccionados como rituales y actividades rutinarias, la disciplina, las estructuras jerárquicas de mando y una serie de rígidos convencionalismos que solamente permiten dar salida a la agresividad sin producir ansiedad, sino que además llegan de hecho a reducir ansiedades cuyo origen puede estar en momentos anteriores a la vida del sujeto".

Tradicionalmente, el rechazo instintivo que la institución militar ha provocado en amplias masas de la población se debe a que Ejército se asocia a guerra ésta a calamidad, muerte, ruina. En defensa de la teoría (que sostienen casi todos los pensadores militares) de que el oficio verdadero del soldado es la paz, el teniente general Díez Alegría, en su libro "Ejército y sociedad"ix recordaba que las más graves y apocalípticas decisiones que se hayan tomado nunca fueron adoptadas por civiles, no por soldados. En defensa de la ética de las armas, el citado autor retoma un expresivo párrafo de la "España invertebrada" de Ortega y Gasset, en la que el pensador escribe:

"Padece Europa una perniciosa propaganda en desprestigio de la fuerza. Sus raíces, hondas y sutiles, provienen de aquellas bases de la cultura moderna que tienen un valor más circunstancial, limitado y digno de superación. Ello es que se ha conseguido imponer a la opinión pública europea una idea falsa de lo que es la fuerza de las armas. Se la ha presentado como cosa infrahumana y torpe residuo de la animalidad persistente en el hombre. Se ha hecho de la fuerza lo contrapuesto al espíritu o, cuando más, una manifestación espiritual de carácter inferior". 


\section{RAZONES HISTÓRICAS DE LA IMAGEN DEL EJÉRCITO ANTE LA SOCIEDAD ESPAÑOLA}

Precisamente, para Ortega, la fuerza espiritual de las armas, según sus propias palabras, radicaba en su carácter persuasivo. El autor de la rebelión de las masas llegó a afirmar que las propias legiones romanas, que tantas guerras provocaron, globalmente, habían servido para evitar más guerras que las propias guerras en las que habían intervenido. En todo caso, dando una de cal y otra de arena, Ortega también afirmaba comprender a los antimilitaristas ${ }^{x}$.

\section{PENSAMIENTO, COMUNICACIÓN Y PUBLICACIONES MILITARES}

Hoy en día, las oficinas de prensa de los diversos departamentos militares, instituciones y servicios cumplen, con creciente profesionalización, la labor de divulgar la propia actividad de las instituciones dedicadas a la defensa nacional y tratan de responder a las preguntas de los periodistas o servir de elemento de contraste de las informaciones más delicadas.

La Revista Española de Defensa es una interesante, pero no completada experiencia. La falta de adecuado lanzamiento y publicidad de apoyo limita el conocimiento de ésta bien construida publicación a muy limitados círculos de interesados, si bien las reducciones económicas ha rebajado los planteamientos con que fue inicialmente concebida, pese a lo cual no se ha resentido su contenido. Junto a los asuntos más específicamente de la defensa nacional, incluye artículos y trabajos de pensamiento, cultura, divulgación y documentación histórica sobre materias militares de rigurosa factura.

Menos conocidas, fuera de los ámbitos profesionales, son las publicaciones específicas "Ejército", la Revista General de Marina o la de Aeronáutica. Estas tres revistas precisan una puesta al día acelerada, sobre todo si las comparamos con revistas parecidas de países de nuestro entorno cultural. Además de las publicaciones específicas de los respectivos estados mayores de los tres ejércitos, el Servicio Histórico Militar posee un interesante fondo, poco conocido fuera de los círculos especializados, pero de enorme interés para quien desee conocer aspectos inéditos de una institución mucho más rica y variada de lo que, a primera vista, pudiera parecer.

España cuenta ya con un no muy numeroso, pero sobresaliente número de pensadores militares, que escriben, analizan y divulgan, incluso desde la crítica, temas de defensa. Resultan de enorme interés los trabajos del coronel e historiador Carlos Blanco, cuyo libro sobre Franco y el general Vicente Rojo -personaje éste por el que siente notable atracción-, trasciende a su objetivo de contraponer la figura del aventurero africanista (Franco) con el militar de estudio y reflexión, Rojo. Son asimismo de enorme interés las aportaciones del ex militar y profesor universitario Gabriel Cardona, cuyo libro "Historia del Ejército" es una espléndida aproximaxión a lo que el autor denominda "un grupo social diferente". Lo mismo cabe decir de las aportaciones del coronel Gonzalo Parente o del general Cuartero, entre otros. 
Pero España no ha recuperado todavía totalmente, pese a notables esfuerzos individuales, en el ámbito de la cultura y el pensamiento militar, el avance y la originalidad de la Colección de Bibliografía Militar, en la que destacaba la altura intelectual de los entonces jóvenes capitanes Emilio Alamán Ortega y, sobre todo, Vicente Rojo Luch, a quienes la guerra colocará en diferentes trincheras.

Los propios historiadores militares del bando nacional reconocen que la nómina de pensadores leales a la República es netamente superior a la de los "africanistas" que se alzaron contra el régimen legalmente vigente en España.

Como escribe Gonzalo Cerezoxi "La CBM ayuda a ver que, en diferentes momentos de la historia española y, particularmente en el horizonte que descubre la Colección, los militares españoles sentaron las bases para la construcción de doctrinas originales, coincidiendo con otros impulsos de renovación que surgían en la sociedad de su tiempo".

En nuestros días, la Editorial Ejército ha continuado, la labor iniciada por la Colección Bibliográfica Militar, que en los últimos cincuenta años ha publicado medio centenar de obras de desiguales contenidos. No obstante, la renovación iniciada en 1978 supuso un revulsivo interesante sobre las etapas anteriores, que hoy en día sigue precisando renovados esfuerzos actualizadores.

No deja de ser curioso reseñar aquí que fue precisamente España el primer país que autoriza la publicación de un periódico militar, hace cerca de cuatrocientos años. En mayo de 1605, las autoridades españolas permitieron la aparición en Holanda de una especie de hoja volandera que recogía detalladamente la crónica de la batalla de Eeckeren, ocurrida apenas unos días antes. El profesor Altabella, catedrático de historia del periodismo español, ha estudiado este interesante antecedente, cuyas reliquias se guardan en la Biblioteca Real de Bruselas ${ }^{\mathrm{xii}}$.

\section{CONCLUSIONES}

A comienzos de los años noventa, según la encuesta nacional del Centro de Investigaciones Sociológicas al respecto, ocho de cada diez españoles consideraban que el Ejército es una institución llamada a desaparecer, mientras casi el 82 por ciento entendían que los militares siempre serían necesarios, en tanto casi el doce de cada cien confesaban no tener opinión al respecto.

La necesidad de considerar que los ejércitos siguen siendo necesarios se agudizaba (caso el 94 por ciento de los encuestados) entre las personas que confiesan ideología de derechas o conservadora. El 72 por ciento de las personas de ideología de izquierda extrema y el 65,5 por ciento de quienes aseguraban no poseer sentimiento religioso declararon justamente lo contrario. 


\section{RAZONES HISTÓRICAS DE LA IMAGEN DEL EJÉRCITO ANTE LA SOCIEDAD ESPAÑOLA}

Curiosamente, la mitad de los españoles piensa que los militares eligen esta profesión por vocación, en tanto casi un tercio opinan que se debe a que es un medio, como cualquier otro de ganarse la vida.

En estos diez años se nota un creciente desinterés, particularmente entre los más jóvenes a propósito de la cuestión militar. En 1990, menos del 57 por ciento de los encuestados creían en la vinculación de los militares con la democracia y su sincera adhesión a la Constitución. En nuestros días, esa confianza ha subido, si bien se mantiene en torno al cuarenta y cinco por ciento la opinión sobre el incremento de prestigio de los militares entre la sociedad. En cambio, casi 38 de cada cien consultados en 1990 que creían que había disminuido no parecen haber cambiado de opinión. xiii $^{2}$

\section{NOTAS}

\footnotetext{
'RAMON y CAJAL, Santiago, Obras Completas, Aguilar, Madrid, 1961, págs. 233 y ss.
}

ii No deja de ser curioso que el mismo caso de corrupción que denuncia Ramón y Cajal se haya repetido, cíclicamente, a lo largo de la reciente historia del Ejército español, con variedades diversas. El 15 de mayo de 1995, el diario "El Mundo del siglo XXI" ponía al descubierto una estafa de enormes proporciones en el Regimiento de Infantería "Canarias 50", en la que se encontraban implicados jefes, oficiales y suboficiales. La estafa al Ministerio de Defensa se producía con el rancho de tropa, ya que mientras solamente comían cada día en el cuartel 150 soldados, se reclamaba al Ministerio raciones para más de mil.

"Un entramado de jefes, oficiales y suboficiales del Regimiento de Infantería Motorizable "Canarias 50", con base en Las Palmas, ha estafado cientos de millones de pesetas al Ministerio de Defensa, sólo en los últimos cinco años, mediante la falsificación de los presupuestos para la alimentación de la tropa, conocida popularmente como "rancho", reveló el periódico, dando cuenta de la implicación en el episodio de un coronel, un teniente coronel, tres capitanes y cinco suboficiales, quienes actuaban de acuerdo con proveedores privados. La unidad contaba con na plantilla de 125 mandos y 800 soldados, de los que solamente menos de 200 comían en el cuartel, aunque se reclamaban y justificaban raciones para más de mil; es decir, por encima incluso de los propios efectivos. La diferencia entre lo consumido y justificado iba directamente a los civiles y militares involucrados en la trama, quienes de este modo llegaban a detraer el erario público una media de quince millones de pesetas mensuales.

Con respecto a este suceso, conviene recordar que una práctica continuada en el Ejército español, dada la precariedad de medios, era aprovechar que una buena parte de los soldados de las guarniciones disfrutaban de "pase de pernocta"; es decir, estaban autorizados a dormir fuera del cuartel, y al mismo tiempo gozaban de rebaje de rancho. Aunque debieran cobrar una cantidad simbólica por este hecho, los fondos correspondientes se destinaban bien a mejorar la alimentación del resto de los soldados menos afortunados o a financiar pequeñas obras e incluso mantenimiento ordinario de las instalaciones cuarteleras. Todos los coroneles recurrían a esta práctica, conocida y tolerada, que era uno de tantos subterfugios para ir tirando y que, en sí misma, era habitual y nunca se consideró ilegal por el mando superior.

iii GIRÁLDEZ LOMBA, Antonio, El año del "Desastre" 1898 en Vigo, Instituto de Estudios Vigueses, Vigo, 2000, pág 256-257. 
iv PAYNE, Stanley G.,Ejército y sociedad en la España liberal (1808-1936), Akal, Madrid, 1977. Págs 160-161.

v “Nuevo Mundo”, Año XII, número 621, jueves, 30 de noviembre de 1905, págs. 14-15.

vi CASTELAO, "Sempre en Galiza", Edicións Galiza, Centro Gallego de Buenos Aires, Instituto Argentino de Cultura Gallega, Buenos Aires, 1974, pág. 195.

vii "La supresión del servicio militar obligatorio. La experiencia de la mili". Informe publicado en el diario EL CORREO GALLEGO, viernes, 24 de mayo de 1996, pág 22.

viii DIXON, Norman F., Sobre la psicología de la incompetencia militar", Anagrama, Barcelona, segunda edición, 1991, pág. 215 y ss.

ix DIEZ ALEGRÍA, Manuel, Ejército y sociedad, Alianza Editorial, Madrid, 1973, pág 43 y ss.

${ }^{\times}$ORTEGA Y GASSET, José, España invertebrada. Bosquejo de algunos pensamientos históricos, Espasa Calpe, Madrid, 1964, págs. 44 y 45.

${ }^{x i}$ CEREZO, Gonzalo, Una aventura intelectual olvidada, Revista Española de Defensa, abril de 1988, págs. 62 y ss.

xii ALTABELLA, José, "Niewe Tydinghen. Primer periódico militar español", Revista Española de Defensa, marzo 1988, pág. 62 y ss.

xiii FERNÁNDEZ del VADO, Santiago, La imagen de los militares ante la sociedad española, Revista Española de Defensa, septiembre de 1990, pág 6 y ss. 